\title{
Effect of Cyclic Fatigue Conditions on Nonlinear Dynamic Viscoelasticity and Fatigue Behaviors for Short Glass-Fiber Reinforced Nylon6
}

\author{
Shintaro Komatsu, Atsushi TAKAHARA ${ }^{*, \dagger}$ and Tisato KAJIYAMA \\ Department of Applied Chemistry, Graduate School of Engineering, Kyushu University, \\ 6-10-1 Hakozaki, Higashi-ku, Fukuoka 812-8581, Japan \\ ${ }^{*}$ Institute for Materials Chemistry and Engineering, Kyushu University, \\ 6-10-1 Hakozaki, Higashi-ku, Fukuoka 812-8581, Japan
}

(Received January 10, 2003; Accepted August 20, 2003)

\begin{abstract}
Fatigue behaviors of short glass-fiber reinforced nylon6 (GF/Ny6) under three cyclic fatigue conditions, tension-tension ( $\mathrm{T}-\mathrm{T})$, tension-compression $(\mathrm{T}-\mathrm{C})$ and compression-compression $(\mathrm{C}-\mathrm{C})$, were investigated on the basis of nonlinear dynamic viscoelastic analysis. A nonlinear viscoelastic parameter $(N V P)$ was used for quantitative evaluation of nonlinear dynamic viscoelasticity for the $(\mathrm{GF} / \mathrm{Ny} 6)$ during the fatigue process. The magnitude of $N V P$ increased with a decrease in the fatigue lifetime under three cyclic fatigue conditions. Under the T-T type cyclic deformation, glass-fibers that lay parallel to the cyclic deformation direction were broken during the fatigue process. After NVP attained a constant magnitude, cracks propagated perpendicularly to the cyclic deformation direction from the glass-fiber ends and ultimately, the (GF/Ny6) was fractured. The stress distribution in the matrix nylon6 became more inhomogeneous due to both glass-fiber breakage and crack propagation, resulting in an increase in $N V P$. In the case of the $\mathrm{C}-\mathrm{C}$ type cyclic deformation, debonding at the (glass-fiber/matrix nylon6) interface occurred during the fatigue process, and the magnitude of $N V P$ was strongly related to the progress of interfacial debonding between glass-fibers and the matrix nylon6. Under the $\mathrm{T}-\mathrm{C}$ type cyclic deformation, the magnitude of $N V P$ increased accompanying crack growth during the tensile deformation process and also, interfacial debonding during the compressive deformation process.

KEY WORDS Fatigue Behavior / Short Glass-Fiber Reinforced Nylon6 / Cyclic Fatigue Condition /

Nonlinear Viscoelastic Parameter/
\end{abstract}

Polymer composites have been widely used as structural components because of their high specific strength or modulus. When polymer composites are applied in structural components, it is necessary to clarify the fatigue mechanism and lifetime to assess their safety.

Fatigue mechanisms of fiber-reinforced polymer composites have been discussed on the basis of fractography. ${ }^{1,2}$ Fractography of the fatigue fracture surface revealed that the fatigue damage of polymer composites starts from debonding at fiber ends, being followed by progressive debonding along the (fiber/polymer) interface until final fracture occurs. In order to investigate the principal change in mechanical properties under cyclic fatigue, the in situ measurement of nonlinear viscoelasticity has been proposed by Kajiyama et al ${ }^{3-11}$ They evaluated a nonlinear viscoelastic parameter, $N V P$, to discuss the nonlinear dynamic viscoelasticity and fatigue mechanisms of polymers during the fatigue process. The magnitude of NVP increased with macroscopic structural damage of short glass-fiber reinforced nylon6 (GF/Ny6) under the tension-compression type cyclic deformation. ${ }^{11}$

Since stress-strain behaviors of polymers depend on the deformation mode such as tensile and compressive deformations, it is important to discuss the fatigue behaviors in tensile and compressive processes during cyclic fatigue deformations. The effects of cyclic fatigue conditions on the fatigue behaviors of polymers have been studied. ${ }^{5,12-15}$ The fatigue lifetime for the extruded high-density polyethylene depended on the cyclic fatigue conditions and increased in the order of the tension-compression ( $\mathrm{T}-\mathrm{C})$, the tension-tension $(\mathrm{T}-\mathrm{T})$, and the compression-compression $(\mathrm{C}-\mathrm{C})$ type cyclic deformation. ${ }^{13}$ In the case of the T-C type cyclic deformation, there were the formation of kink-band during compressive deformation and the extension of the kink-band boundary region during tensile deformation, resulting in the propagation of cracks along the kink-band boundary. Therefore, the fatigue lifetime under the $\mathrm{T}-\mathrm{C}$ type cyclic deformation decreased in comparison with those under the $\mathrm{T}-\mathrm{T}$ and $\mathrm{C}-\mathrm{C}$ type cyclic deformations. Since the compressive deformation does not contribute to the crack growth, the fatigue lifetime under the $\mathrm{C}-\mathrm{C}$ type cyclic deformation is longer than the case of the T-T type cyclic deformation. Also, the fatigue behavior for polystyrene (PS) under various cyclic fatigue conditions was investigated on the basis of the nonlinear viscoelasticity measurement. ${ }^{5}$ The fatigue lifetime for PS increased in the order of the T-T, $\mathrm{T}-\mathrm{C}$, and $\mathrm{C}-\mathrm{C}$ type cyclic deformation. Since crazes

${ }_{\dagger}^{\dagger}$ To whom correspondence should be addressed (Tel: +81-92-642-2721, E-mail: takahara@cstf.kyushu-u.ac.jp). 
being formed in the tensile deformation process accelerated the progress of fatigue damage, the fatigue lifetime of the T-T type cyclic deformation was shortest among the three type cyclic deformations. The magnitude of nonlinear viscoelasticity under the $\mathrm{T}-\mathrm{C}$ type cyclic deformation was higher than those under the $\mathrm{T}-$ $\mathrm{T}$ and $\mathrm{C}-\mathrm{C}$ type cyclic deformations. In the $\mathrm{T}-\mathrm{C}$ type cyclic deformation, the unsymmetrical stress response might be induced due to a larger compressive response and smaller tensile one, because the compressive modulus of PS was higher than the tensile one. Therefore, the large nonlinear dynamic viscoelasticity might arise from the remarkably unsymmetrical wave of stress response in the case of the $\mathrm{T}-\mathrm{C}$ type cyclic deformation.

In this study, the nonlinear dynamic viscoelastic characteristics for the (GF/Ny6) were investigated under three cyclic fatigue conditions, and the fatigue mechanisms were discussed on the basis of the nonlinear dynamic viscoelastic analysis and the morphological observation.

\section{EXPERIMENTAL}

\section{Material}

The specimen used in this study was short glass-fiber reinforced nylon6 (GF/Ny6), which has been widely applied as structural components of automobiles. The matrix polymer of nylon6 (commercial grade, UBE Nylon 1015B) was supplied from Ube Industries, Ltd. Surface-modified short glass-fibers being treated with aminosilane coupling agent were used as a reinforcing component. The diameter and average length of glassfibers were $c a .13 \mu \mathrm{m}$ and $c a .400 \mu \mathrm{m}$, respectively. The fraction of glass-fibers in the (GF/Ny6) was fixed to be $30 \mathrm{wt} \%$. The ASTM-D1822 Type L tension-impact specimen of the (GF/Ny6) was prepared by an injection molding. It was apparent from SEM observation of the cross-section of the (GF/Ny6) that the glass-fibers almost oriented along the molding direction, that is, the longitudinal direction of the specimens. The dimensions of dumb-bell shape specimen were $20 \mathrm{~mm}$ in gauge length, $3.18 \mathrm{~mm}$ in width and $3.0 \mathrm{~mm}$ in thickness.

\section{Evaluation Method of Fatigue Behavior for (GF/Ny6) on the Basis of Nonlinear Viscoelastic Analysis}

The fatigue behavior for the (GF/Ny6) was evaluated using a homemade fatigue tester that can monitor nonlinear dynamic viscoelasticity during cyclic deformation. ${ }^{11}$ Sinusoidal strain with the constant amplitude was imposed on the specimen. The frequency of cyclic straining was $11 \mathrm{~Hz}$ and the ambient temperature under nitrogen gas atmosphere was $303 \mathrm{~K}$. The cyclic fatigue conditions were the tension-tension ( $\mathrm{T}-\mathrm{T})$, the tensioncompression $(\mathrm{T}-\mathrm{C})$ and the compression-compression (C-C) type cyclic deformations. The strain ratio was $\varepsilon_{\min } / \varepsilon_{\max }=0$ under the $\mathrm{T}-\mathrm{T}$ type cyclic deformation, $\varepsilon_{\min } / \varepsilon_{\max }=-1$ under the $\mathrm{T}-\mathrm{C}$ type cyclic deformation and $\varepsilon_{\max } / \varepsilon_{\min }=0$ under the $\mathrm{C}-\mathrm{C}$ type cyclic deformation, respectively. Here, $\varepsilon_{\max }$ and $\varepsilon_{\min }$ indicate the maximum and minimum applied strain, respectively. The surface temperature of the (GF/Ny6), $T_{\mathrm{s}}$, was measured at the middle of the specimen with a pair of adhesivetype thermocouples. It was confirmed that thermocouples did not influence the deformation and stress distribution for the (GF/Ny6) during the fatigue process. The surface temperature rise, $\theta$, was obtained by subtracting the ambient temperature from $T_{\mathrm{s}} . \theta$ was continuously monitored during the fatigue process.

The fatigue behavior was discussed on the basis of a nonlinear viscoelastic parameter, $N V P$ which corresponded to an extent of nonlinearity of dynamic viscoelasticity. ${ }^{3-11}$ The magnitude of $N V P$ was calculated from the coefficients of fourier expanded series of a response stress signal during the fatigue process, as follows:

$$
N V P=\frac{\sigma_{2}+\sigma_{3}+\cdots+\sigma_{10}}{\sigma_{1}}
$$

where $\sigma_{1}$ is the fundamental stress amplitude and $\sigma_{2}, \sigma_{3}, \cdots, \sigma_{10}$ indicate the higher-order harmonic stress amplitude. Therefore, the magnitude of NVP increases with increasing nonlinearity of dynamic viscoelasticity for a specimen.

\section{Fracture surface morphology of (GF/Ny6)}

Morphology of fatigue fracture surfaces of the (GF/Ny6) samples after T-T, T-C, and C-C type cyclic fatigue was observed using a scanning electron microscope (SEM) (S-2150, Hitachi, Ltd.). The fracture surface of the (GF/Ny6) was coated with gold to avoid charging of the specimen during SEM observation.

\section{Measurement of Glass-Fiber Length for (GF/Ny6)}

The glass-fiber length of the (GF/Ny6) before and after fatigue tests under three type cyclic deformations was measured. Glass-fibers were recovered from the (GF/Ny6) as follows. The matrix nylon6 of the (GF/Ny6) before and after the fatigue tests was melted and then, the glass fibers at the central parts of each (GF/Ny6) sample were used to measure their lengths. Therefore, the parts were dissolved in $m$-cresol and then, glass-fibers were collected by filtration. The photographs of glass-fibers were taken with an optical microscope and then, the length of glass-fibers was measured using image-processing software (NIH Image, National Institutes of Health, Bethesda, MD, USA). 
The sampling number of measurements was 1800 .

\section{RESULTS AND DISCUSSION}

Relationship between Dynamic Strain Amplitude and Fatigue Lifetime for (GF/Ny6) under Three Cyclic Fatigue Conditions

Figure 1 shows the relationship between the imposed strain amplitude, $\varepsilon_{\mathrm{d}}$ and the fatigue lifetime for the (GF/Ny6) under the T-T, T-C, and C-C type cyclic deformations at $11 \mathrm{~Hz}$ and $303 \mathrm{~K}$. In the case of the imposed strain amplitude larger than $1.2 \%$, the fatigue lifetime decreased in the order of the $\mathrm{T}-\mathrm{C}, \mathrm{C}-\mathrm{C}$, and $\mathrm{T}-\mathrm{T}$ type cyclic deformation at the same magnitude of strain amplitude. The dynamic strain amplitude of $1.2 \%$ corresponds to the maximum strain of $2.4 \%$ under the T-T type cyclic deformation and the minimum strain of $-2.4 \%$ under the $\mathrm{C}-\mathrm{C}$ type cyclic deformation. Figure 2 shows the $\mathrm{S}-\mathrm{S}$ curves for the (GF/Ny6) at the deformation rate of $1.0 \mathrm{~mm} \mathrm{~min}^{-1}$ under static tensile and compressive deformations from an unstressed

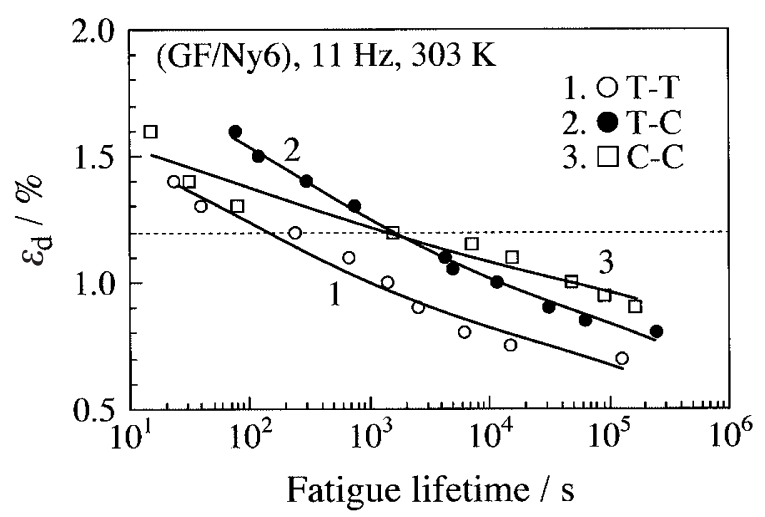

Figure 1. Relationship between imposed strain amplitude, $\varepsilon_{\mathrm{d}}$ and fatigue lifetime for the (GF/Ny6) under three type cyclic deformations at $11 \mathrm{~Hz}$ and $303 \mathrm{~K}$. Solid lines are drawn for the guidance of eye.

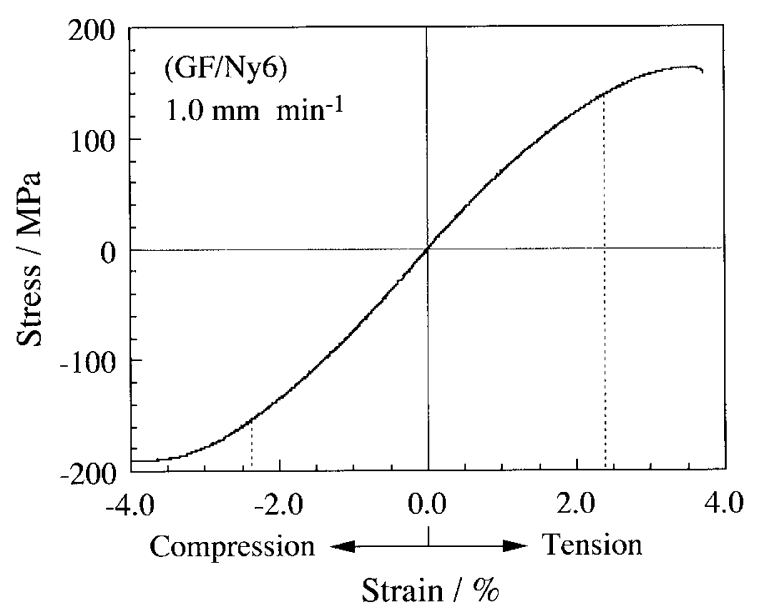

Figure 2. Stress-strain curves for the (GF/Ny6) under static tensile and compressive deformation. state. The strain of $\pm 2.4 \%$ was close to the yield points for both the tensile and compressive deformations of the (GF/Ny6). Therefore, Figure 2 indicates that plastic deformation or failure occurred at an initial stage under cyclic fatigue of strain amplitude larger than 1.2\% in the case of the $\mathrm{T}-\mathrm{T}$ and $\mathrm{C}-\mathrm{C}$ type cyclic deformations. This apparently corresponds that the fatigue lifetime under the $\mathrm{T}-\mathrm{T}$ and $\mathrm{C}-\mathrm{C}$ type cyclic deformations remarkably decreased in comparison with that under the $\mathrm{T}-\mathrm{C}$ type cyclic deformation, as shown in Figure 1. At the strain amplitude smaller than $1.2 \%$, the fatigue lifetime decreased in the order of the $\mathrm{C}-\mathrm{C}, \mathrm{T}-\mathrm{C}$, and $\mathrm{T}-\mathrm{T}$ type cyclic deformation at the same magnitude of strain amplitude. The fatigue lifetime decreased with an increase in the amount of tensile deformation during cyclic strain. In order to clarify the difference in the fatigue lifetime, the fatigue behaviors at small strain amplitude among three type cyclic deformations will be discussed in the following section.

Fatigue Behaviors for (GF/Ny6) on the Basis of Nonlinear Viscoelastic Analysis

Figure 3 shows the fatigue time dependence of dynamic storage modulus, $E^{\prime}$, surface temperature rise, $\theta$ and nonlinear viscoelastic parameter, $N V P$, for the

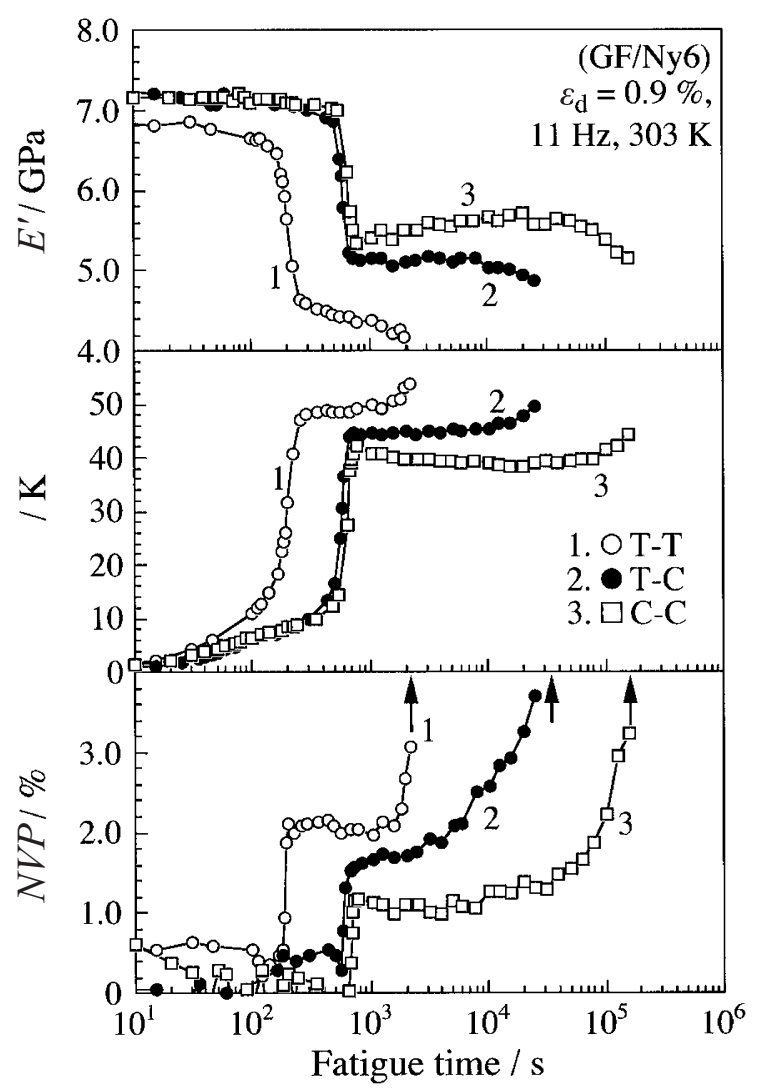

Figure 3. Variations of $E^{\prime}, \theta$, and $N V P$ for the (GF/Ny6) with time during the fatigue process at the imposed strain amplitude of $0.9 \%$ under three type cyclic deformations at $11 \mathrm{~Hz}$ and $303 \mathrm{~K}$. 
(GF/Ny6) at the small dynamic strain amplitude of $0.9 \%$ under the $\mathrm{T}-\mathrm{T}, \mathrm{T}-\mathrm{C}$, and $\mathrm{C}-\mathrm{C}$ type cyclic deformations at $11 \mathrm{~Hz}$ and $303 \mathrm{~K}$. The magnitudes of $N V P$ under three type cyclic deformations were lower than $1 \%$ during the initial process of fatigue tests. In this study, the period up to a remarkable step increase in $N V P$ is defined as an initial stage. Since cracks were generally formed in the tensile deformation process resulting in an acceleration of the progress of fatigue damage, the fatigue time at the steep increase in NVP under the $\mathrm{T}-\mathrm{T}$ type cyclic deformation was shortest among three type cyclic deformations, as shown in Figure 3.

Relationship between Imposed Strain Amplitude and NVP for $(G F / N y 6)$

It was clarified in our previous study that the magnitude of $N V P$ apparently increased due to interfacial debonding between glass-fibers and the matrix nylon6 in the $(\mathrm{GF} / \mathrm{Ny} 6) .{ }^{11}$ As shown in Figure 3, the magnitudes of NVP under three type cyclic deformations markedly increased at a critical fatigue time after several hundred seconds from the start of fatigue tests and then, remained constant values which were defined as $N V P_{\mathrm{S}}$ in this study.

Figure 4 shows the relationship between the imposed strain amplitude, $\varepsilon_{\mathrm{d}}$ being lower than $1.2 \%$ and the magnitude of $N V P_{\mathrm{S}}$ under three type cyclic deformations at $11 \mathrm{~Hz}$ and $303 \mathrm{~K}$. The magnitude of $N V P_{\mathrm{S}}$ increased in the order of the $\mathrm{C}-\mathrm{C}, \mathrm{T}-\mathrm{C}$, and $\mathrm{T}-\mathrm{T}$ type cyclic deformation. An increase in $N V P_{\mathrm{S}}$ and a decrease in fatigue lifetime corresponded together. These results indicated that the deformation types exerted a significant effect on the nonlinear dynamic viscoelasticity for the (GF/Ny6), since the fatigue process was different between the tensile and compressive deformations. In order to discuss the relationship be-

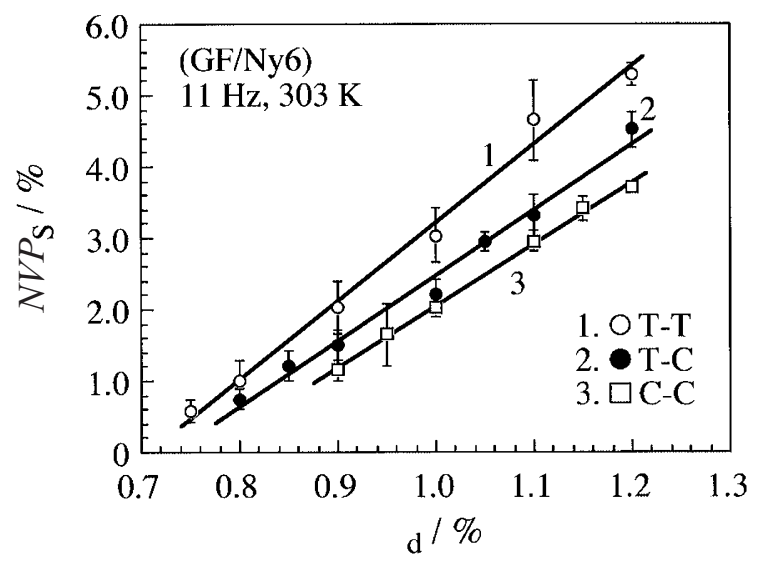

Figure 4. Relationship between imposed strain amplitude, $\varepsilon_{\mathrm{d}}$ and $N V P_{\mathrm{S}}$ for the $(\mathrm{GF} / \mathrm{Ny} 6)$ under three type cyclic deformations at $11 \mathrm{~Hz}$ and $303 \mathrm{~K}$. tween the nonlinear dynamic viscoelasticity and the fatigue mechanisms under tensile and compressive deformation process, morphological observation of the (GF/Ny6) based on SEM was carried out.

\section{Morphological Observation of (GF/Ny6) and Measure- ment of Glass-Fiber Length}

Figure 5 shows the cross-section morphology for the (GF/Ny6), which was obtained after the cyclic fatigue until the magnitude of $N V P$ reached $3.1 \%$ under the $\mathrm{T}-\mathrm{T}$ type cyclic deformation. The direction of glassfibers orientation was parallel to that of cyclic deformation in the SEM image. The formation of void at a glass-fiber end and the breakage of glass-fiber were observed. The crack propagated connecting voids and broken fibers during the fatigue process under the $\mathrm{T}-\mathrm{T}$ type cyclic deformation.

Figure 6 shows the cross-section morphology for the (GF/Ny6), which was obtained after the cyclic fatigue until the magnitude of $N V P$ reached $2.8 \%$ under the $\mathrm{C}-$ $\mathrm{C}$ type cyclic deformation. The debonding at the interface between glass-fiber surface and the matrix nylon6 was observed. On the other hand, the breakage of glassfiber was not observed on the cross-section. Figure 7 clearly indicates that the interfacial debonding occurred along the glass-fiber surface during the fatigue process under the $\mathrm{C}-\mathrm{C}$ type cyclic deformation and finally, the (GF/Ny6) was fractured.

Figure 7 shows SEM images of fatigue fracture sur-

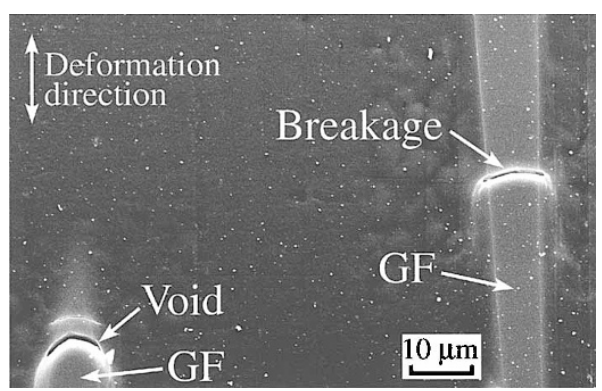

Figure 5. SEM image of cross-section morphology for the (GF/Ny6) under the tension-tension type cyclic deformation.

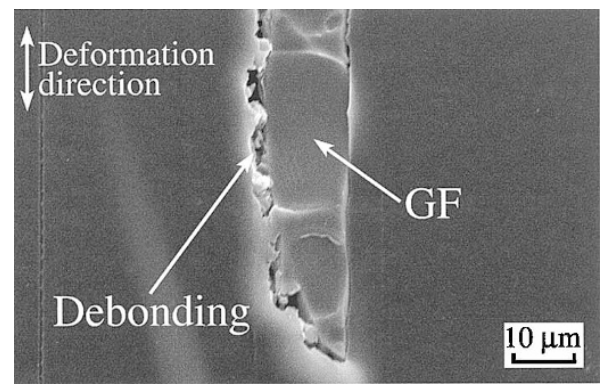

Figure 6. SEM image of cross-section morphology for the (GF/Ny6) under the compression-compression type cyclic deformation. 


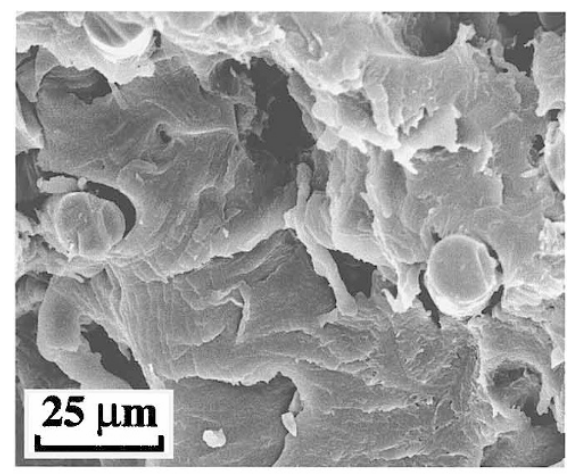

(a) T-T type

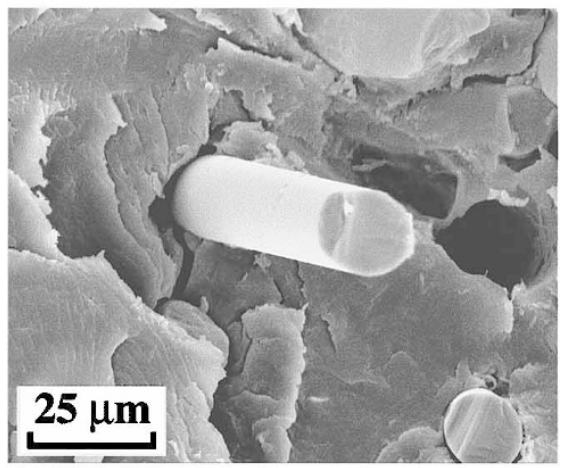

(b) T-C type

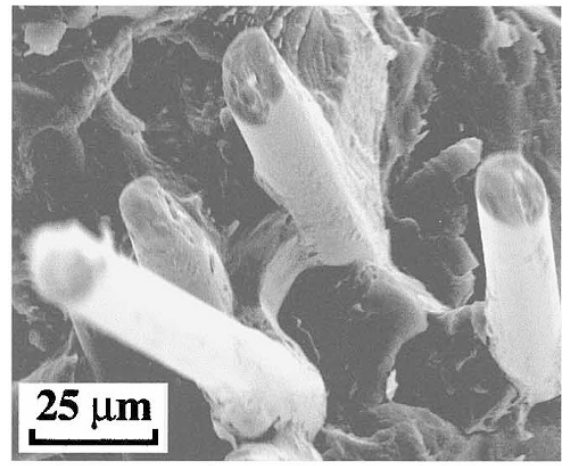

(c) C-C type

Figure 7. SEM images of fatigue fracture surface for the (GF/Ny6) under three type cyclic deformations.

face for the (GF/Ny6) under three type cyclic deformations. In the case of the $\mathrm{T}-\mathrm{T}$ type cyclic deformation (Figure 7a), most of glass-fibers were broken and the fairly flat areas were extended in the matrix nylon6, which implied that the radial propagation of cracks rapidly occurred from broken glass-fibers. Under the $\mathrm{T}-\mathrm{C}$ type cyclic deformation (Figure $7 \mathrm{~b}$ ), some glassfibers were pulled out from the matrix nylon6. Under the $\mathrm{C}-\mathrm{C}$ type cyclic deformation (Figure $7 \mathrm{c}$ ), almost all glass-fibers were pulled out and the pull-out length of fibers was larger than that under the $\mathrm{T}-\mathrm{T}$ and $\mathrm{T}-\mathrm{C}$ type cyclic deformations. Figure 7 apparently shows that the morphology of fracture surface for the (GF/Ny6) depended on the types of cyclic deformation, as well as glass-fiber length in the fractured (GF/Ny6).

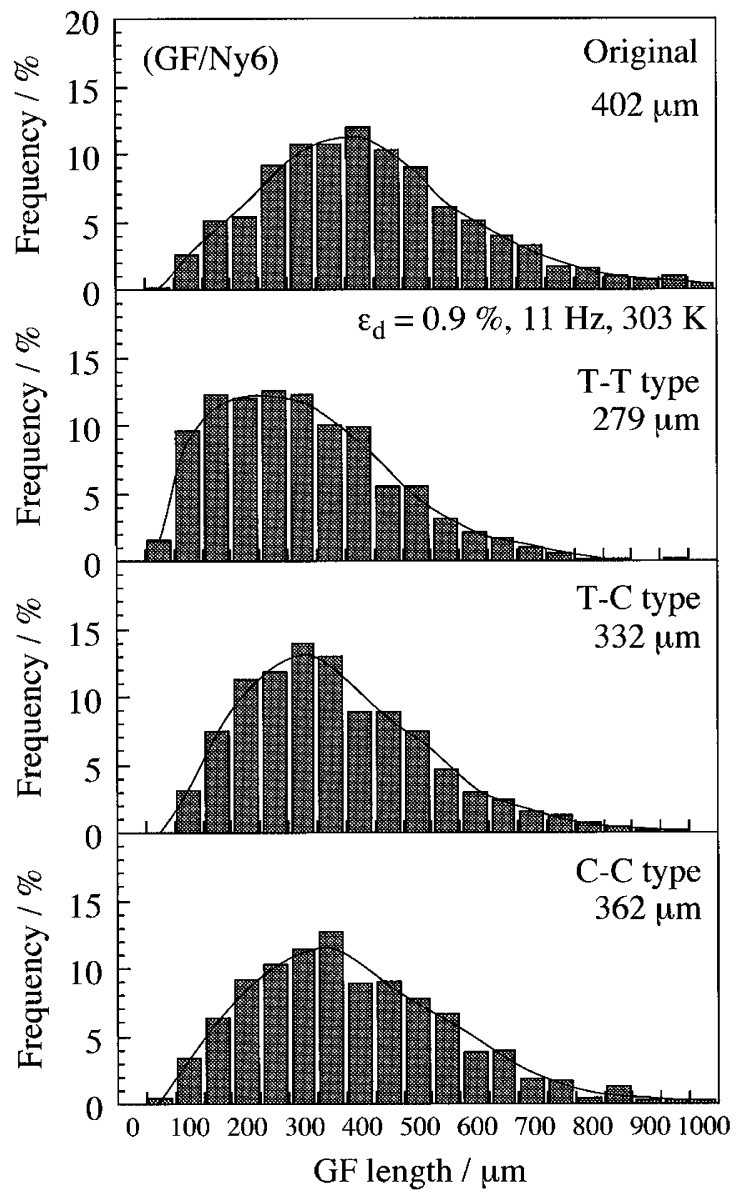

Figure 8. Distribution of glass-fiber length for the (GF/Ny6) under three type cyclic deformations.

Figure 8 shows the distribution of glass-fiber length near the fracture surface for the (GF/Ny6) being subjected to the $\mathrm{T}-\mathrm{T}, \mathrm{T}-\mathrm{C}$, and $\mathrm{C}-\mathrm{C}$ type cyclic deformations. Under the $\mathrm{T}-\mathrm{T}$ type cyclic deformation, the number of glass fibers with $c a .100 \mu \mathrm{m}$ to $c a .200 \mu \mathrm{m}$ in length increased. With regard to the SEM observation and the measurement of glass-fiber length, glass fibers were broken during the fatigue process under the $\mathrm{T}-\mathrm{T}$ type cyclic deformation. On the other hand, the number of glass fibers with shortest length under the $\mathrm{C}-\mathrm{C}$ type cyclic deformation were almost same as that before fatigue test. Also, the glass-fiber length at the maximum frequency for the $\mathrm{C}-\mathrm{C}$ type test was similar to the original one before fatigue test and on the other hand, that for T-T type test shifted to shorter length in comparison with the original glass-fiber. Therefore, it is reasonable to consider that the interfacial debonding along glassfiber surface occurred and then, glass fibers were pulled out from the matrix nylon6 during the fatigue process under the $\mathrm{C}-\mathrm{C}$ type cyclic deformation.

Fatigue Fracture Mechanisms under $T-T, T-C$, and $C-$ C Type Cyclic Deformations

The fatigue fracture mechanisms for the (GF/Ny6) 


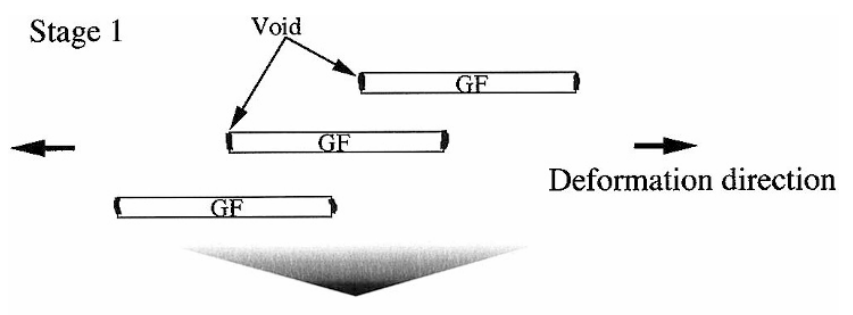

Stage 2

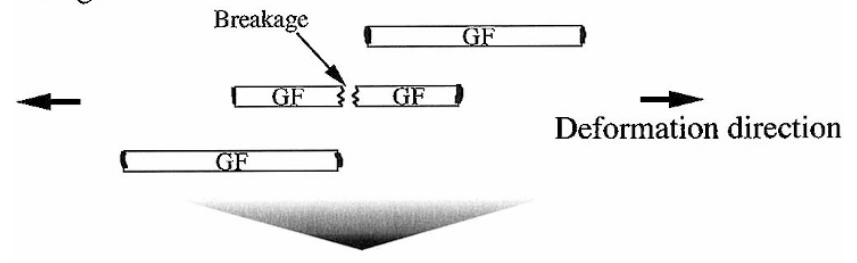

Stage 3

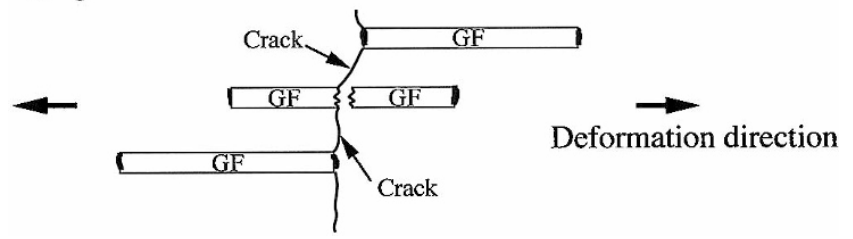

Figure 9. Schematic representation of fatigue fracture process for the (GF/Ny6) under the tension-tension type cyclic deformation.

under three type cyclic deformations were discussed on the basis of the nonlinear dynamic viscoelastic analysis and the morphological evidence. Figure 9 shows the fatigue fracture process under the T-T type cyclic deformation. First, voids were formed at glass-fiber ends due to concentration of shear stress in tensile deformation (Figure 9, stage 1). Next, long glass-fibers were broken during a fatigue process (Figure 9, stage 2). This may be occurred at the mechanically weak part of glass fiber. These defects might be formed during the molding process. The void formation and glass-fiber breakage induce an increase in strain amplitude in the (GF/Ny6) whole and then, the magnitude of deviation in the wave shape of response stress amplitude from a sinusoidal wave became prominent, resulting in an increase in NVP. The magnitude of NVP under the T$\mathrm{T}$ type cyclic deformation in the initial stage increased due not only to the nonlinearity of S-S curves but also to the void formation and fiber breakage. Cracks propagated from voids perpendicular to the tensile deformation direction connecting voids and broken fibers in the matrix nylon6. It seems reasonable to consider that the response stress amplitude decreased around cracks and increased at crack tips. Therefore, the magnitude of deviation in the stress wave shape increased and the magnitude of NVP markedly increased. Finally, the (GF/Ny6) was fractured (Figure 9, stage 3).

Figure 10 shows the fatigue fracture process under the $\mathrm{C}-\mathrm{C}$ type cyclic deformation. In this case, voids were not formed at glass-fiber ends because the com-
Stage 1

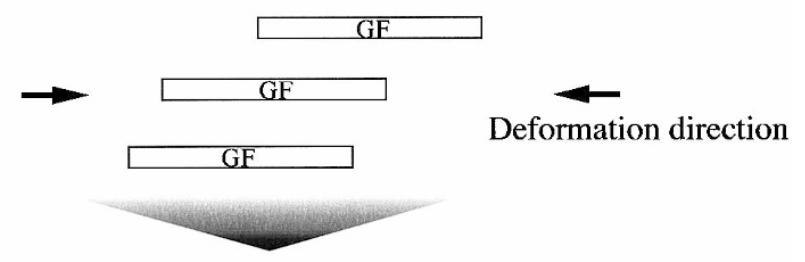

Stage 2

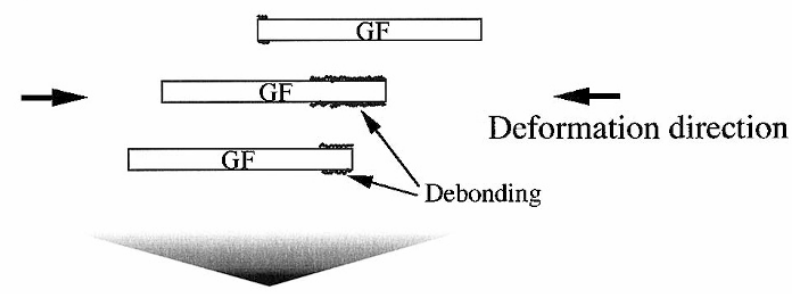

Stage 3

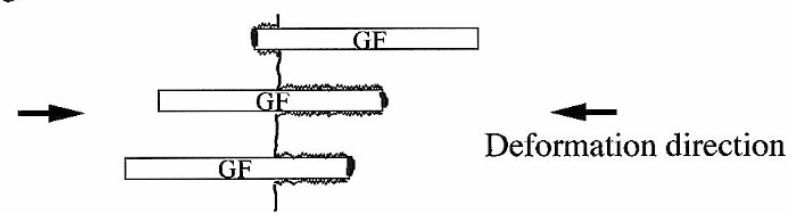

Figure 10. Schematic representation of fatigue fracture process for the (GF/Ny6) under the compression-compression type cyclic deformation.

pressive deformation process accompanied void and crack closure (Figure 10, stage 1). Since the modulus of glass-fiber was much higher than that of matrix nylon6, debonding occurred at the interfacial region along glass-fiber surface (Figure 10, stage 2). The interfacial debonding led to the non-uniform distribution of imposed strain amplitude. Therefore, the stress wave shape deviated from a sinusoidal wave and the magnitude of $N V P$ increased. Ultimately, the (GF/Ny6) was fractured (Figure 10, stage 3). The interfacial shear strength between glass-fiber and the matrix nylon6 was $44 \mathrm{MPa}$ and the tensile strength for the (GF/Ny6) was $160 \mathrm{MPa}$. Since the shear strength was much smaller than the tensile strength, the distribution of imposed strain amplitude during the progress of interfacial debonding under the $\mathrm{C}-\mathrm{C}$ type cyclic deformation was more homogeneous than that during the glass-fiber breakage and crack growth under the $\mathrm{T}-\mathrm{T}$ type cyclic deformation. Therefore, the deviation of wave shape of response stress amplitude was small under the $\mathrm{C}-\mathrm{C}$ type cyclic deformation, and the magnitude of $N V P$ decreased in comparison with that under the $\mathrm{T}-\mathrm{T}$ type cyclic deformation. We confirmed that plastic deformation occurred under the T-C type cyclic deformation at the interfacial region during the fatigue process by SEM observation in our previous study. ${ }^{11}$ During the fatigue process under the $\mathrm{T}-\mathrm{C}$ type cyclic deformation, cracks were formed and propagated under tensile deformation and interfacial debonding occurred un- 
der compressive deformation. The magnitude of $N V P$ under the $\mathrm{T}-\mathrm{C}$ type cyclic deformation increased due to the crack growth and interfacial debonding.

\section{CONCLUSIONS}

The nonlinear dynamic viscoelastic analysis was employed to evaluate the effect of cyclic fatigue conditions on the fatigue behavior of the (GF/Ny6). The magnitude of a nonlinear viscoelastic parameter, NVP increased in the order of the compression-compression, the tension-compression and the tension-tension type cyclic deformation. In the case of the tensiontension type cyclic deformation, the response stress wave markedly deviated from a sinusoidal wave due to void formation, glass-fiber breakage and crack growth. Therefore, the magnitude of $N V P$ increased under the tension-tension type cyclic deformation. Under the compression-compression type cyclic deformation, the interfacial debonding led to deviation of response stress wave from a sinusoidal shape, resulting in an increase in NVP. Under the tension-compression type cyclic deformation, NVP increased because of both crack growth and interfacial debonding.

Acknowledgments. The authors thank Mr. Kazuya Noda (Asahi Chemical Industry Co., Ltd.) for the preparation of specimens and helpful discussions.

\section{REFERENCES}

1. R. W. Lang, J. A. Manson, and R. W. Hertzberg, J. Mater. Sci., 22, 4015 (1987).

2. J. J. Horst and J. L. Spoormaker, J. Mater. Sci., 32, 3641 (1997).

3. N.-J. Jo, A. Takahara, and T. Kajiyama, Polym. J., 25, 721 (1993).

4. N.-J. Jo, A. Takahara, and T. Kajiyama, Polym. J., 26, 1024 (1994).

5. T. Liang, K. Tokunaga, A. Yamashita, A. Takahara, and T. Kajiyama, Polym. Bull., 36, 477 (1996).

6. T. Liang, A. Takahara, and T. Kajiyama, Polym. J., 28, 801 (1996).

7. N.-J. Jo, A. Takahara, and T. Kajiyama, Polymer, 38, 5195 (1997).

8. T. Liang, A. Takahara, K. Saito, and T. Kajiyama, Polymer, 39, 5387 (1998).

9. S. Komatsu, A. Yamashita, A. Takahara, and T. Kajiyama, Rep. Progr. Polym. Phys. Jpn., 42, 327 (1999).

10. K. Noda, A. Takahara, and T. Kajiyama, Polymer, 42, 5803 (2001).

11. S. Komatsu, A. Takahara, and T. Kajiyama, Polym. J., 34, 897 (2002).

12. C. B. Bucknall and W. W. Stevens, J. Mater. Sci., 15, 2950 (1980).

13. N. Kaiya, A. Takahara, and T. Kajiyama, Polym. J., 21, 523 (1989).

14. M. G. Wyzgoski, G. E. Novak, and D. L. Simon, J. Mater. Sci., 25, 4501 (1990).

15. D. A. Baker, R. S. Hastings, and L. Pruitt, Polymer, 41, 795 (2000). 